

\title{
CIDADES COMPACTAS E VERDES: DISCUSSÕES ACERCA DA QUALIDADE DE VIDA E SUSTENTABILIDADE URBANA
}

\author{
GREEN AND COMPACT CITIES: DISCUSSIONS REGARDING QUALITY \\ OF LIFE AND URBAN SUSTAINABILITY
}

CIUDADES COMPACTAS Y VERDES: DISCUSIONES ACERCA DE LA

CALIDAD DE VIDA Y LA SOSTENIBILIDAD URBANA

\author{
Edson Leite Ribeiro ${ }^{1}$ \\ Geovany Jessé Alexandre Da Silva ${ }^{2}$ \\ José Augusto Ribeiro Da Silveira ${ }^{3}$
}

\begin{abstract}
Resumo
No contexto contemporâneo, em que a dispersão (sprawl) e a fragmentação urbana se disseminam, afetando inclusive algumas cidades europeias tradicionalmente mais compactas e densas, o paradigma da cidade compacta pode vir a se apresentar como uma alternativa viável, embora não Ihe faltem críticos. Este estudo analisa vantagens e desvantagens do modelo compacto em relação à proposição norte-americana do smart growth. A pesquisa objetivou examinar os dois modelos por meio de uma comparação dos impactos urbanos sobre a natureza, incluindo o consumo energético, os espaços naturais e a qualidade de vida da população, utilizando-se indicadores espaciais urbanísticos e de qualidade de vida da população. Como procedimento metodológico, partiu-se de algumas hipóteses construídas a partir da teoria existente e adotaram-se alguns modelos de índices de compactação urbana utilizados internacionalmente. Por intermédio de simulações, chegou-se a conclusões referentes à disponibilidade e à acessibilidade a elementos qualitativos urbanos, bem como à simulação da percepção desses mesmos elementos por parte da comunidade. Como resultado, verificou-se que, embora em alguns casos, os indicadores quanti-qualitativos de um modelo urbano mais expansivo pareçam melhores pela quantidade disponibilizada de espaços láreas verdes, por exemplo), por outro lado, a sua efetiva utilização pode ocorrer melhor e mais eficientemente em cidades mais compactas, seja pela possibilidade de melhor distribuição espacial e acessibilidade, seja pelo dimensionamento mais apropriado (por exemplo, à escala humana), o que torna o seu potencial de utilização mais otimizado. Os resultados permitem desmistificar os argumentos de uma suposta qualidade ambiental e disponibilidade real em uma estruturação mais extensiva, oferecendo respostas objetivas à escolha de princípios de desenho urbano mais sintético, denso, verde e sustentável.
\end{abstract}

Palavras-chave: Cidades Compactas e Verdes. Qualidade de Vida Urbana. Sustentabilidade Urbana. 


\begin{abstract}
In the contemporary context, where the dispersion (sprawl) and urban fragmentation spread, affecting even some European cities traditionally more compact and dense, the paradigm of compact city can come to present itself as a viable alternative, although there are many critics. This study examines the advantages and disadvantages of compact model in relation to the US proposition of smart growth. The research aimed to examine both models through a comparison of urban impacts on nature, including energy consumption, natural spaces and the population's quality of life, using urban space indicators and people's quality of life. As methodological procedure, started by some hypotheses diagnosed from the existing theory and adopted to some models of urban compression ratios used internationally. Through simulations, we reached conclusions regarding the availability and accessibility to urban qualitative elements as well as the simulation of the perception of these same elements from the community. As a result, it was found that even if in some cases the quantitative and qualitative indicators of a more expansive urban model may look better by the amount of available space (e.g.green areas), in other respects, their effective use can occur better more efficiently and more compact cities, is the possibility of better spatial distribution and accessibility, is the most appropriate sizing (e.g., human scale), which makes its potential use more optimized. The results allow demystify the arguments of an alleged environmental quality and real availability in more extensive structuring, offering objective responses to the choice of principles of urban design more synthetic, dense, green and sustainable.
\end{abstract}

Keywords: Compact and Green Cities. Quality of Urban Life. Sustainable Urban.

\title{
Resumen
}

En el contexto actual, donde la dispersión (sprawl) y la fragmentación urbana se propagan, afectando incluso a algunas ciudades europeas tradicionalmente más compactas y densas, el paradigma de la ciudad compacta pueden llegar a presentarse como una alternativa viable, aunque no carece de sus críticos. Este estudio examina las ventajas y desventajas del modelo compacto en relación con la propuesta norteamericana de un crecimiento inteligente. La investigación tuvo como objetivo examinar los dos modelos, a través de una comparación de los impactos urbanos en la naturaleza, incluyendo el consumo de energía, de los espacios naturales y sobre la calidad de vida de la población, a través de indicadores de ordenación urbana y calidad de vida de las personas. Como procedimiento metodológico, empezamos con algunas hipotesis construidas a partir de la teoría existente y adoptadas para algunos modelos de relaciones de compresión urbanas utilizadas internacionalmente. A través de simulaciones, llegamos a conclusiones con respecto a la disponibilidad y accesibilidad a los elementos cualitativos urbanas, así como la simulación de la percepción de estos elementos por parte de la comunidad. Como resultado, se encontró que, aunque en algunos casos los indicadores cuantitativos y cualitativos de un modelo urbano más expansivo se ven mejor sobre la cantidad disponible de espacio (zonas verdes, por ejemplo), por otra parte, su uso real puede ocurrir mejor y de manera más eficiente en las ciudades más compactas, sea por la posibilidad de una mejor distribución espacial y la accesibilidad, sea por el tamaño más apropiado (por ejemplo, a escala humana), lo que hace su uso potencial más optimizado. Los resultados nos permiten desmitificar los argumentos de una supuesta calidad ambiental y la disponibilidad real de una estructuración más extensiva, proporcionando respuestas objetivas a la elección de los principios de diseño urbano más sintéticos, densos, verdes y sostenibles.

Palabras clave: Ciudades compactas y verdes. Calidad de vida urbana. Urbanismo sostenible.

\section{Introdução}

Nas últimas décadas, a adesão à proposta da compactação urbana tem crescido significativamente entre os urbanistas do mundo, particularmente na Europa continental, onde o sprawl urbano, embora ocorrido com voracidade menor que nos Estados Unidos e outras regiões do mundo, tem sido indesejado, em função do alto impacto negativo que tem provocado sobre 
o espaço rural e o entorno natural, incluindo as culturas agrícolas tradicionais como os vinhedos e as atividades vinhateiras, importante elemento da cultura e da economia rural de vários países do continente europeu. A dependência automotiva é outro fator importante nesse processo, uma vez que se produz um vasto território urbano de baixa densidade (de unidades habitacionais unifamiliares) e de separação de usos e há uma dissolução da escala humana (pedonal) para acesso às partes da cidade, distanciando a relação entre o habitar, o trabalho e o lazer/recreio, em decorrência da necessidade de circulação. Diversos outros fatores podem ser elencados, tais como a segregação socioespacial, o encarecimento da infraestrutura e a manutenção dos sistemas urbanos, o isolamento de comunidades, a pouca coesão social, o alto grau de emissão de gases e a maior demanda de recursos, resíduos e energias.

Muitos estudos preconizam ou colocam a cidade compacta como um modelo adequado à sustentabilidade urbana, embora se deva considerar que essa hipótese não é consensual. Em parte, porque alguns estudos não tiveram sucesso em demonstrar, com clareza, o seu melhor desempenho ambiental ou sustentável em relação à cidade dispersa. Outros autores buscam uma solução alternativa entre o sprawl e a cidade compacta, propondo o smart growth. Nessa última proposta, tenta-se apresentar alternativas de composição entre estruturas urbanas difusas, com assentamentos mais nucleados e com possibilidades pontuais de redução do uso da circulação veicular individual. A contradição está no fato de que essas propostas não dão uma resposta sistêmica ao funcionamento da cidade, como um todo, mas de forma fragmentada, apresentando soluções somente acessíveis por meio do mercado imobiliário de luxo. As estruturas resultantes parecem mais uma collage do que um sistema coerente. Nesse âmbito estão também as propostas enquadradas no "Novo Urbanismo" norte-americano, que aparentam certa coerência interna, no entanto representam apenas simulações de um suposto sistema espacial equilibrado, sem apresentar boa sinergia sistêmica com o restante da cidade. Todavia, é uma proposta de intensificação do uso urbano em um espaço de cidade dispersa.

Entre os críticos da cidade compacta, um dos argumentos mais utilizados tem sido o da suposta baixa qualidade de vida urbana, motivada por uma possível escassez de espaços abertos e naturais no espaço intraurbano. Há quem sustente que em uma cidade compacta o ambiente seria mais "sufocante". No entanto, essa suposição seria verdadeira? Qual a dimensão ideal dos espaços livres e verdes urbanos? Qual seria a proporção ideal entre os espaços e volumes edificados e os espaços livres? Há quem diga que a cidade que tem espaços livres e verdes intraurbanos bastante avantajados, em relação às outras, seria sempre a melhor. Seria uma hipótese comprovável?

Há que considerar também o fato de que a obsessão por grandes quantidades de espaços livres e verdes muitas vezes é pensada para a escala do automóvel e não para escala humana e nem das funções coletivas, dos vínculos comuni- 
tários e da coesão social. Em muitos casos, seria mais apropriado chamar os "espaços públicos" de "distâncias públicas", em função do dimensionamento desproporcional na escala do pedestre. Os eixos monumentais, os grandes canteiros verdes centrais em vias expressas, os extensos gramados dos cruzamentos e interseções rodoviárias não são espaços utilizáveis pelo pedestre. São espaços gerados para a escala de utilização e velocidade do automóvel, mas não são espaços adequados ao uso humano e social. Por outro lado, o encontro das pessoas, a dinâmica das interações humanas, de lazer e cultura são muito distintas entre as cidades compactas e dispersas, sendo, para a primeira, intensificados os seus usos, enquanto que, na segunda, a área verde per capita maior acaba por dispersar a população em espaços públicos e policentros da cidade de usos menos intensos.

Ao se observarem algumas cidades, notam-se as preferências de permanência de pedestres sobre os espaços livres, destacando-se que: a) na "cidade modernista" (caso de Brasília ou Chandigarh), os espaços mais adensados em setores comerciais têm uma permanência humana bem maior que os grandes eixos, grandes gramados em espaços monumentais e vias axiais secundárias; b) nas cidades europeias, os calçadões de pedestres e dos cafés e lojas, bem como os espaços dos centros de origem medieval e dos séculos XVIII e XIX, têm a preferência da permanência pelos cidadãos em relação aos eixos viários principais, diagonais e outros espaços de maior velocidade automobilística; c) os corredores de lojas nos atuais shopping centers, na prática, reproduzem um espaço em que as pessoas comumente se encontram, em referência, talvez, aos espaços aconchegantes dos estreitos calçadões de pedestres em núcleos urbanos tradicionais ${ }^{4}$. No entanto, nos ditos shopping centers, um simulacro de espaços centrais de outrora, vive-se uma realidade fictícia, simulada, cenográfica e bastante contraditória. Enquanto se simula cenograficamente um espaço interno típico para pedestres, em seus "bastidores", ao contrário, pode-se observar um "mar" de estacionamentos, exatamente porque a estrutura de funcionamento de um shopping center, diferentemente do que sua aparência cenográfica propõe, foi feita para o automóvel. Essa "nulidade real" pode ser vista como o aspecto mais destacado de sua característica de "não-lugar". O desenho de agrupamentos comerciais, a partir de um zoneamento urbano monofuncional, é resultado da separação das funções urbanas no território disperso, conectados por vias, (des)integrando áreas urbanas de baixa densidade e de ênfase automotiva individual. As cidades norte-americanas são exemplos mundiais desse modelo urbano, como a cidade de Atlanta, uma das mais dispersas do mundo. (Figura 1)
4. Bem certo, de diferente em relação aos espaços públicos tradicionais, mesmo em sua área cenográfica, está o foco centralizado em um único verbo: consumir, ao invés de serem espaços onde o "se encontrar" e o "se relacionar" ou "se conviver" sejam suas características mais importantes. A própria função de mercado, carregado de profundo sentido de relacionamento social (de trocas), se descaracteriza-se desstes elementos, no funcionamento do comércio globalizado e automatizado do mercado contemporâneo. 

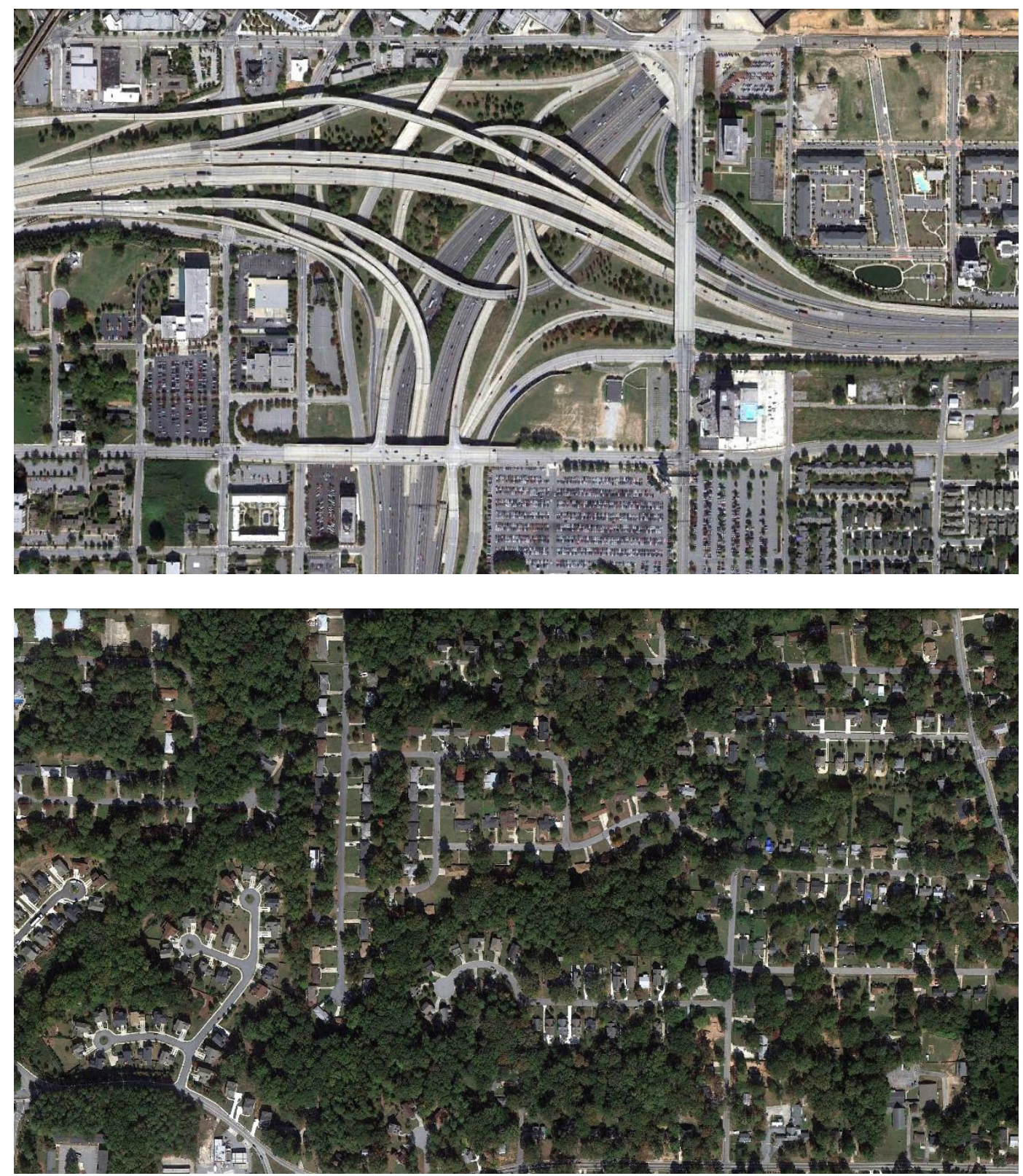

O desenho de bairros de baixa densidade (por volta de 10 hab/ ha) induz à dependência automotiva individual, que leva a uma legislação indutora do automóvel e dos sistemas viários, em virtude das necessidades de deslocamento entre trabalho, casa e lazer, sob um alto custo per capita de urbanização e manutenção dos sistemas urbanos. Embora se viva sobre uma verdadeira apologia ao automóvel e ao ciclo vicioso de dependência automotiva (transportes X ocupação e uso do solo/ planejamento urbano e regional), no fundo, as preferências inconscientes das pessoas ainda são os espaços pedestriani
Figura $1 \bullet$ Desenho urbano disperso de Atlanta (2012) na área central comercial e de serviços (acima), repleto de vias e estacionamentos, e no subúrbio habitacional (abaixo), de casas espaçosas e muita área verde.

Fonte: Autores, adaptado de Google Earth (2012).

Cadernos de Arquitetura e Urbanismo, v.23, n.33, 20 sem. 2016 


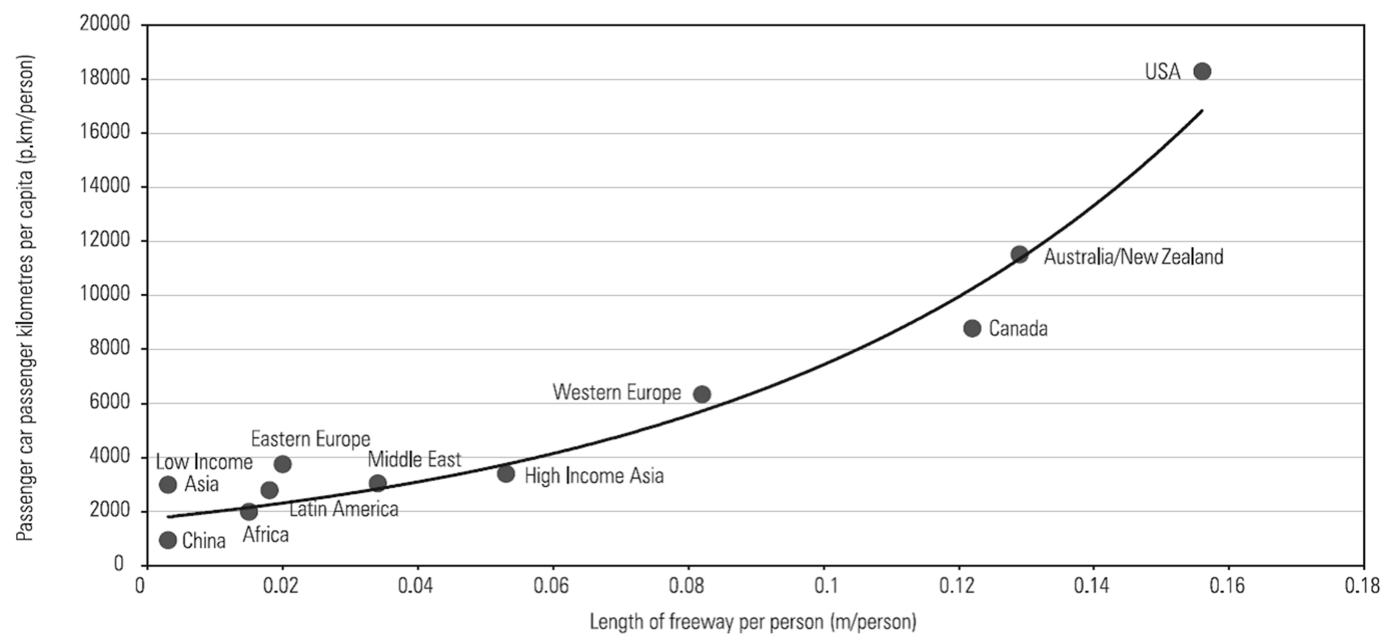

Source: Adapted from: Kenworthy 2003

zados e os espaços apropriados para o relacionamento social, não motorizado. A preferência inegável da sociedade ainda é pelo lugar pleno de significados sociais e culturais, e não pelo "não-lugar", plenos apenas de signos. De fato, como menciona um manifesto do Milano-Lab (2005):

(...) precisamos habituar-nos a projetar antes de tudo os espaços das relações humanas e não prioritariamente os espaços físicos. O projeto dos espaços físicos representa a conseqüência ou a condição, pode influir ou valorizar um projeto mas, antes de tudo, é necessário projetar para o modo, o sentido e o objetivo com que as pessoas vivem, individualmente e em sociedade. [sic] (Milano-Lab, mídia, 2005).

Desse modo, a adoção de modelos estruturais e dimensionais urbanos que permitam essa prioridade do espaço de permanência e de relacionamentos humanos sobre os demais seria urgente, tanto para a qualidade de vida quanto para a sustentabilidade.

Como princípio, toma-se o conceito da cidade como um sistema urbano e como um sistema espacial. Para tanto, considerar-se-ia como sistema espacial o "grupo de elementos interligados e organizados de maneira a funcionar em conjunto, visando à otimização de trocas e de fluxos, de relacionamentos, informações, energia e matéria".5

Para o conceito de sistema urbano, pode ser adotado o seguinte: "sistema espacial organizado de forma a otimizar a qualidade de vida e a prestação de serviços à população". Ainda na mesma linha de conceituação, se fôssemos qualificar o sistema urbano de um ecossistema urbano equilibrado, ou relativo a uma cidade sustentável, poderíamos
Figura 2 • Relação entre comprimento de estrada por pessoa e quilômetro percorrido por passageiros para algumas regiões e países, em 2003.

Fonte: Silva (2011) apud UN-HABITAT (2008: 176) / Kenworthy, 2003.

5. De fato, a origem da Teoria Geral dos Sistemas, proposta por Von Bertalanffy (1950 e 1968), tem sua origem no funcionamento orgânico interno de seres vivos e em sua extrapolação para organismos compostos, em queonde a importância do funcionamento conjunto do organismo era considerado superior ao funcionamento individual de cada orgão ou parte isolada. Dessta maneira, no sistema urbano, a collage de pequenas partes que funcionam bem internamente, mas não se relacionam bem no conjunto, não são capazes de adicionar qualidade ao seu funcionamento.

Cadernos de Arquitetura e Urbanismo, v.23, n.33, 20 sem. 2016 
acrescentar ao conceito anterior a seguinte extensão: “(...) qualidade de vida e a prestação de serviços à população de forma igualitária para as gerações presentes e para as futuras gerações (intra-geracional e inter-geracional)".

Portanto, dentro do sistema urbano, bem como dentro da origem histórica da cidade, apesar de todas as contradições geradas historicamente também por diferentes formas de exploração, fica evidenciado a sua condição coletiva e social. Uma grande contradição existente na forma de se "resolver" as questões intraurbanas contemporâneas é o seu caráter particular, específico, individual, parcial e não coletivo. Essa contradição faz a cidade se tornar uma "collage" não sistêmica, onde os seus elementos não se interagem e não se integram. A fragmentação de espaços em virtude de interesses especulativos e a produção de "áreas nobres" (gentrificação, por exemplo) resultam em invasões não reconhecidas pela gestão urbana nas áreas periféricas, ou mesmo a obsolescência e abandono de áreas centrais mais antigas e desvalorizadas (em parte, face às legislações patrimoniais). Esse processo pode ser verificado em diversos cenários urbanos no mundo ocidental.

\section{Aplicações de avaliação da dispersão urba- na por indicadores}

Neste capítulo, foi elaborado um apanhado acerca de procedimentos metodológicos aplicados à análise da dispersão urbana, com o intuito de se apresentar um breve cenário do estado da arte desse campo de estudo, a partir das teorias existentes e, dentre as quais, adotaram-se também alguns modelos de índices de compactação urbana utilizados internacionalmente. A partir desses índices espaciais, é possível avaliar comparativamente distintos casos urbanos, por meio da utilização de simulações de potencialidades para os modelos mais compactos, os modelos mais dispersos e outros mais próximos do conceito de smart growth. Dessa comparação, pode-se chegar a conclusões referentes à disponibilidade e à acessibilidades a elementos qualitativos urbanos, bem como à sua percepção e ao potencial de utilização por parte da comunidade.

De forma geral, a dispersão urbana não é medida apenas pela sua extensão superficial. Conforme Maignant (2004), além da relação entre a sua extensão superficial e sua densidade demográfica e construída, três indicadores básicos de sua característica bidimensional são utilizados: a) a relação superfície urbana/perímetro urbano; b) a relação entre a superfície da cidade e a superfície de um círculo circunscrito teórico, e c) a relação entre um círculo inscrito e um círculo circunscrito teóricos. Entre os índices básicos mais utilizados, estão os índices de Gravélius (1914), Miller (1953) e Morton (2003) (apud MAIGNANT, 2004), indicados a seguir: 


\begin{tabular}{|c|c|c|}
\hline Indice de Miller & Indice de Morton & Indice de Gravélius \\
\hline I Miller $=\frac{4 \Pi . S}{\mathrm{P}^{2}}$ & I Morton $=\frac{\mathrm{S}}{\Pi(0,5 \cdot \mathrm{T})^{2}}$ & I Gravélius $=\frac{\mathrm{P}}{2 \sqrt{\Pi} . \mathrm{S}}$ \\
\hline
\end{tabular}

Onde: $\mathrm{S}=$ Superficie (área)

$\mathrm{P}=$ Perímetro urbano

$\mathrm{T}=$ Índice de dispersão, ou seja, a maior dimensão entre todas as direções

Portanto, não se trata apenas de uma questão quantitativa (área superficial), mas também de configuração, composição, proporção ou morfologia espacial, além de suas densidades. Dessa forma, uma cidade de maior área superficial pode ser mais compacta do que uma área urbana de menor área superficial, desde que suas densidades e seus aspectos morfológicos definam estruturas menos dispersas ou fragmentadas. ${ }^{6}$

\section{A Necessidade de um Funcionamento Si- nérgico e Ecológico de um Sistema Espa- cial Urbano Sustentável}

Diante do evidenciado, o problema que parece tornar inatingível ou, pelo menos, insolúvel, refere-se ao funcionamento insustentável do espaço urbano que reside exatamente na falta de sinergia sistêmica no funcionamento da cidade. Um sistema, por definição, deve ser um conjunto de elementos que, mesmo funcionando diferentemente entre si, trabalhem em conjunto e de forma harmônica. Assim, um sistema espacial, entre os quais também se enquadra o sistema urbano, deveria funcionar sob um sistema harmônico e eficiente. $\mathrm{Na}$ gestão do tempo e do espaço, dentro do sistema urbano, duas coisas são absolutamente essenciais dentro de um sistema espacial: a) a maior aproximação possível da condição isotrópica plena, e b) a maior otimização possível dos espaços e dos dispositivos que permitam ou facilitem a sua utilização para a qualidade de vida de seus habitantes.

A eficiência máxima de um sistema espacial urbano ocorre no funcionamento da isotropia. Um sistema espacial isotrópico é aquele em que as condições de acessibilidade são (em condições de homogeneidade) iguais a cada fase de expansão espacial do sistema. De certa forma, é um sistema que apresenta uma analogia bastante forte ao modelo gravitacional. Nesse modelo, todas as camadas se mantêm equidistantes (isonomia espacial e de acessibilidades) do centro polarizador e fornecedor de bens e serviços.
Quadro 1 • Índices básicos utilizados para análise da dispersão urbana.

Fonte: Autores, 2013

6. Nos três índices, a melhor condição configuracional, que seria representada pelo círculo, que demonstra a isotropia perfeita, teria o índice 1, considerado o mais próximo do equilíbrio. A única diferença entre os índices é que enquanto os índices de Miller e Morton variam entre 0 (pior condição, em queonde a dispersão é maior) e 1 (condição isotrópica perfeita), o índice de Gravélius é um índice negativo: o ideal é 1, mas a medida em que se aumenta a dispersão, aumenta-se o valor do índice. 


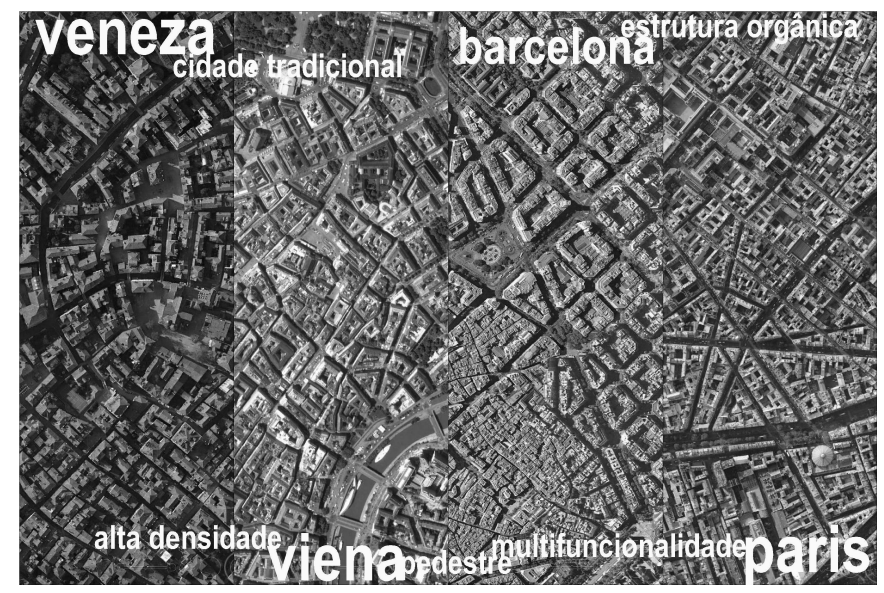

Evidentemente, uma isonomia total no plano físico e social (socioeconômico, cultural, físico-natural, físico-estrutural urbano, etc.), que conduziria a uma isotropia plena, é uma hipótese muito mais teórica que prática, abstrata. No entanto, o princípio apresenta uma coerência espacial perfeita. As "deformações" inseridas a partir desse modelo, permitidas pela diversidade cultural e social, pelos condicionamentos de várias vertentes, a exemplo da fisiografia natural, funcionamento do sistema regional, etc., além de exprimir a forma cultural própria de resolução do espaço, vão definir as potencialidades ou as novas necessidades a cada setor, segundo o nível de distanciamento da condição isotrópica. Em geral, as condições mais próximas da isotropia permitem muito mais potencialidades de uso e menor dependência do que as soluções espaciais que se distanciam dela.

Em uma condição isotrópica facilita-se a não dependência de sistemas mecânicos ou motorizados para a circulação, embora pela sua dimensão, às vezes o exija, quando as distâncias a serem percorridas, mesmo na condição otimizada, afastem-se da escala espaço-temporal desejável para o caminhar humano, dentro do ritmo de funcionamento da cidade contemporânea. Além disso, o próprio uso do sistema mecânico e motorizado, em uma condição mais isotrópica, também ocorre dentro da condição otimizada, uma vez que as densidades são importantes para o funcionamento de um sistema de atendimento coletivo, como o sistema de transporte público. Essa viabilidade é otimizada em cidades mais compactas, pois se atende a um número maior de pessoas por metro quadrado de sistema de transporte coletivo, barateando tais serviços.

Mas ainda existem cidades totalmente apropriadas para o caminhar humano. São, em geral, cidades de conformação medieval ou com soluções espaciais semelhantes, com boa densidade e diversidade de ocupação e usos. Embora essa situação urbana não seja tão comum na realidade brasileira atual e nas cidades do continente americano, alguns setores urbanos poderiam localmente estabelecer as condições para tal utilização. A densidade de ocupação, a diversidade e a "mixité" de usos são essenciais para sua viabilização. As
Figura $3 \bullet$ Veneza, Viena, Barcelona e Paris: Exemplos de estruturas urbanas isotrópicas puras (concêntricas, em princípio) de traçado tradicional (medieval), caracterizadas por densidade bruta elevada, sobreposição de usos, traçado orgânico e escala humana dos espaços. Condições bem viáveis e acessíveis para a pedestrianização da circulação.

Fonte: Geovany J. A. Silva, 2013. 
áreas centrais urbanas tradicionais são bons exemplos dessa possibilidade. Contudo, poucas cidades utilizam coerentemente esses diferentes aspectos espaciais e estruturais existentes no seu interior, segundo a sua real potencialidade.

A própria conformação difusa, porém, nuclearizada das cidades, poderia favorecer também o uso de sistemas coletivos na circulação urbana, com nucleações em torno de pontos ou linhas de sistemas de transportes coletivos, minimizando os raios de deslocamento pedonal entre os moradores/usuários e a estação. No entanto, as soluções espaciais dispersas ou mais fragmentadas, sem nucleações definidas, induzem a uma difusão bem maior de sua circulação, incentivando ou mesmo quase obrigando ao uso do automóvel. A priorização da utilização do automóvel, que é considerado um sistema de transporte individual ${ }^{7}$ (pois, apesar da capacidade média de 4 passageiros, em nenhum lugar do mundo, a média de passageiros efetivos por viagem atingiu o índice 2), vem constituir um equívoco no funcionamento intraurbano, pela sua natureza individual e não coletiva da solução, como demandaria o sistema urbano intrinsecamente coletivo.

Em face disso, o transporte rodoviário se tornou um devorador de espaço urbano e de energia de fontes fósseis. De fato, quanto mais a cidade se dispersa, mais as distâncias se tornam grandes, inviabilizando os transportes não motorizados, e mais as densidades se tornam rarefeitas, inviabilizando os sistemas coletivos de transportes motorizados. Dessa forma, à medida que a propagação de veículos individuais aumenta, rapidamente preenche-se os espaços viários, pela sua elevada voracidade no consumo de espaços para circulação, levando o sistema congestionado a um baixo nível de eficiência.

A insistência na resolução da questão por meio do automobilismo, na prática, acaba agravando o problema, uma vez que a abertura de novas vias e o alargamento das existentes acabam estimulando o uso do automóvel, continuando o círculo vicioso e direcionando o planejamento urbano a novos espaços para os automóveis, seja para circular, seja para estacionar. O que poderia ter um efeito mais positivo seria a reestruturação da cidade para uma organização físico-territorial mais densa. Contudo, a estrutura atual, particularmente em cidades norte-americanas e latino-americanas, já muito dispersas, também reduz as possibilidades de viabilização da eficiência dos corredores e linhas de transportes, como elementos influentes na reestruturação da urbe.
7. O automóvel é considerado um transporte individual, apesar de ter, em geral, capacidade para 4 ou 5 pessoas, uma vez que em nenhum país a média de passageiros por automóveis em circulação atingiu o índice de 2 passageiros/veículo. Os índices médios situados no intervalo de 1,4 e 1,7 passageiros por veículo são os índices mais comuns. 


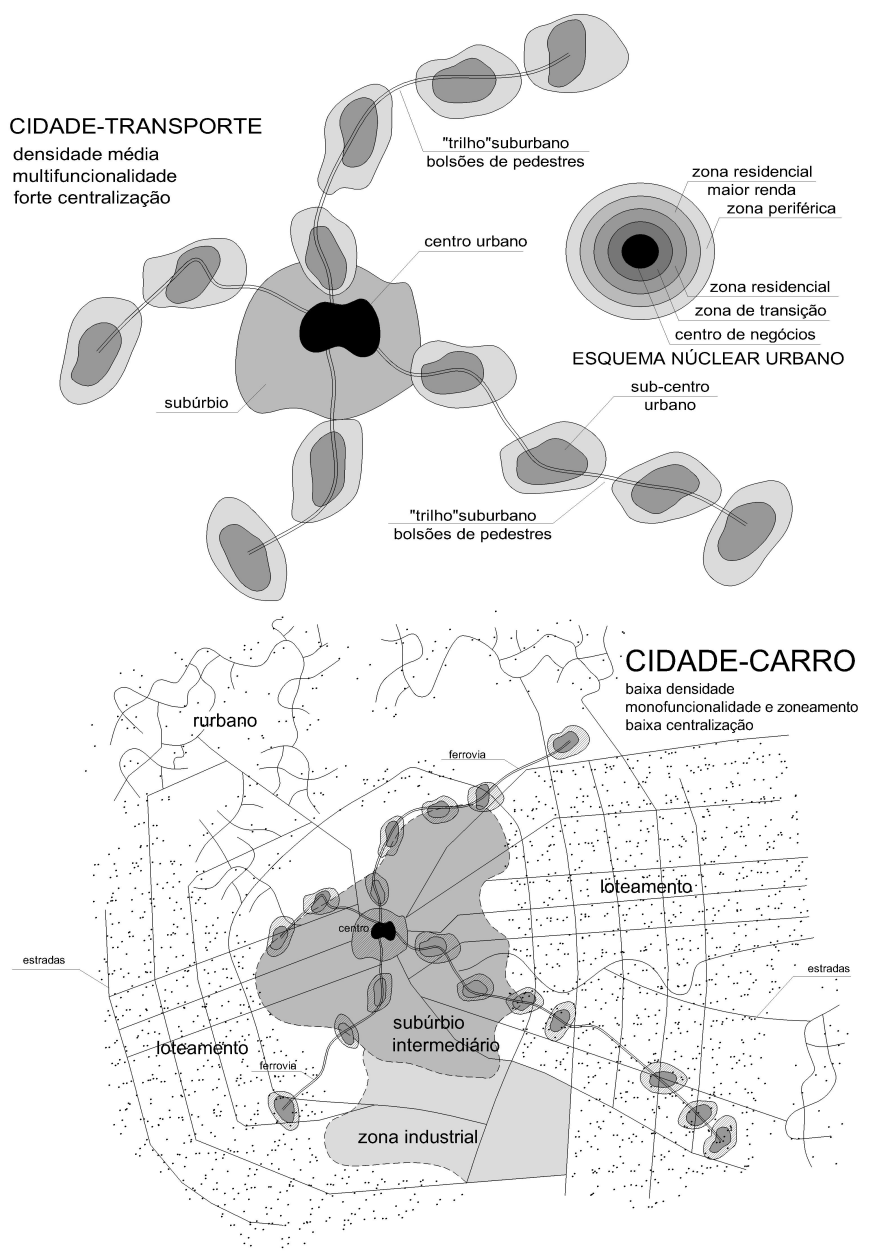

Também nas estruturas urbanas mais estendidas (Figura 4), a sua estruturação nuclearizada em torno de eixos regionais de transportes facilitam mais as soluções coletivas do que a estruturação completamente difusa De fato, segundo Bochet, Gay \& Pini (2004), existe uma ligação bastante estreita entre as formas urbanas, a densidade, a diversidade de usos e a mobilidade. Numerosos estudos, além dos autores citados, também demonstram que os volumes de fluxos, as distâncias e os meios de deslocamentos são não apenas influenciados, mas determinados pela morfologia urbana. Uma cidade mais densa pode favorecer a diversidade e os deslocamentos de curta distância, bem como a utilização de transportes públicos coletivos. Por outro lado, cidades difusas ou dispersas, com distâncias internas mais longas e setorização especializada, conduzem sempre à forte dependência do automóvel.

Dentro de uma visão histórica, também pode se indagar se a difusão urbana não seria exatamente uma negação do caráter coletivo da cidade? A natureza coletiva da "polis" ou da "civitas" não estaria a caminho de sua destruição? Em uma visão sociológica, por meio da abordagem da urbanidade, muitos autores, como Levy (1994), conjeturam que o enfraquecimento das centralidades urbanas é o prenúncio de
Figura 4 - Estruturas urbanas estendidas.

Fonte: Autores / LAURBE, 2013 
uma vitória do individualismo contra o aspecto comunitário e social das cidades. Essa questão, de certa forma, encontra pontos comuns em relação à tese levantada por Claval (2000), a qual demonstra que é exatamente no centro urbano que cada cidadão se funde em um grande ser coletivo, que é a comunidade urbana.

De fato, até mesmo em seu sentido físico, os espaços centrais têm seu efeito de dupla convergência: a convergência física, que leva ao encontro social e à integração físico-espacial, e a convergência cultural e simbólica, na qual as pessoas individualmente e as comunidades urbanas se identificam e se reinventam a cada dia.

\title{
O Sistema Urbano Compacto e suas influ- ências sobre a Sustentabilidade e a Quali- dade de Vida
}

\begin{abstract}
A busca da cidade como espaço adequado à vida humana tem sido constante e é mostrada pela tendência histórica de evolução da taxa de urbanização, em diversos períodos e em diversos graus de dificuldades na vida urbana. Ainda em períodos de grandes problemas sociais, de epidemias, de conflitos, de desigualdades, a sociedade humana parece reinventar a sua esperança na cidade. De fato, a ideia de que "o ar da cidade liberta" parece se conservar ao longo do tempo e a torna sempre atrativa, ainda que, no contexto urbano recente, busque-se dispersar sua estrutura, mantendo as estruturas urbanas e rurais, bem como as distâncias interpessoais, em níveis contraditórios. Se em 1950 a população urbana mundial era de $29 \%$ de um total de 2,5 bilhões de pessoas, atualmente já ultrapassou $50 \%$ da população total estimada em mais de 7 bilhões. Essa última será, segundo as estimativas, a cifra estimada da população urbana (com 70\% do total), quando em 2050 atingiremos quase 10 bilhões de indivíduos, ou seja, a população atual do mundo será, em menos de quatro décadas, a população urbana mundial. O modelo urbano disperso atual, todavia, já apresenta seus limites e problemas (Figuras 5 e 6).
\end{abstract}



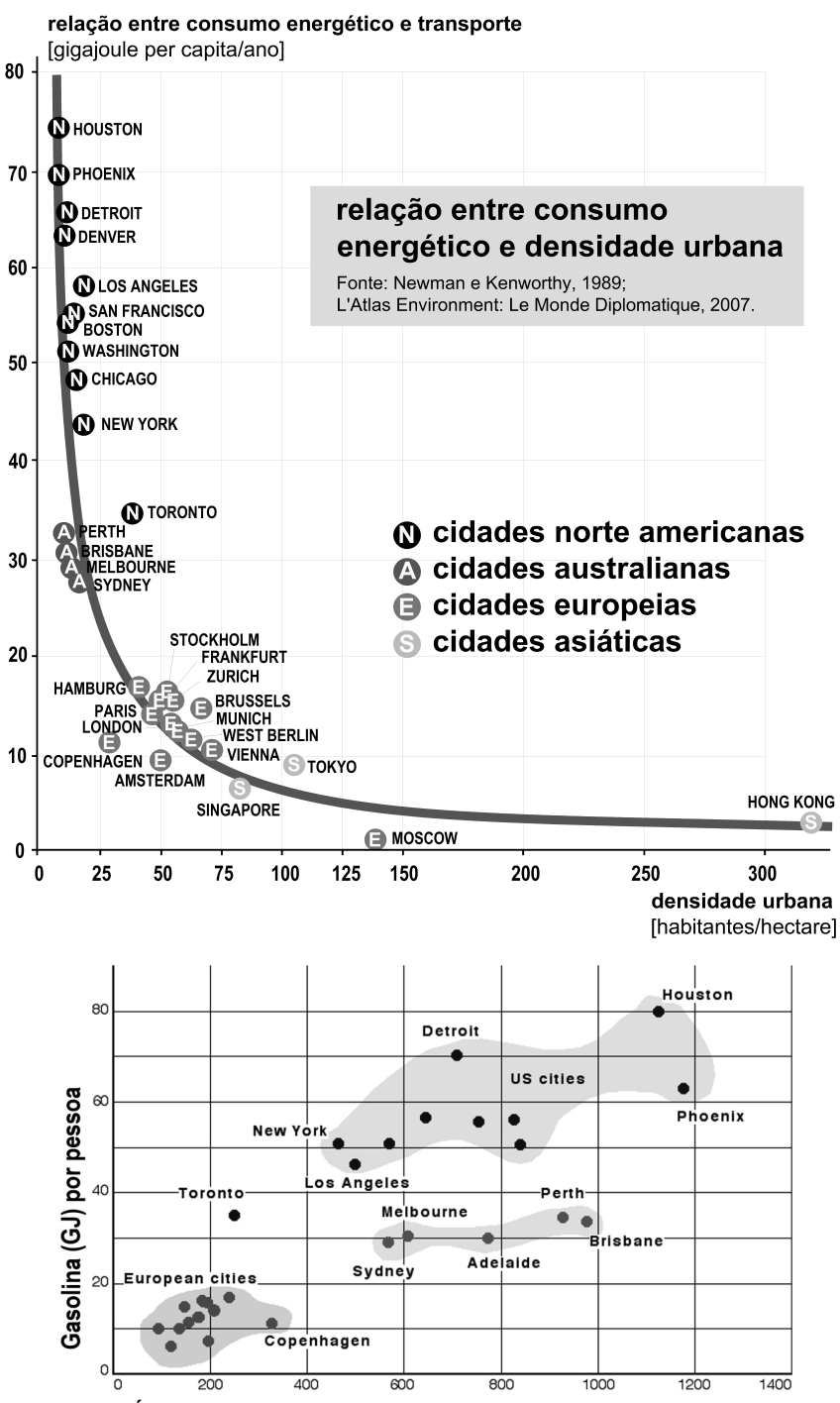

Área (metro quadrado) por pessoa

Provavelmente, a cultura contemporânea, de caráter bem mais individualista que comunitário ou solidário, seja um dos motivos desse "distanciamento" intraurbano. Outro motivo bem claro seria a adequação do desenho urbano à escala de velocidade do automóvel, com as distâncias adaptadas a tal. Esse fator associado ao conteúdo especulativo, seletivo e de invenção do "novo", presentes no mercado imobiliário, faz com que a cidade acabe ocupando áreas bem maiores que a sua real necessidade.

Nada obstante, podem-se compreender aspectos espaciais de dispersão urbana, de forma mais aclarada, por meio de exemplos próximos, tomando-se como base a cidade de João Pessoa, capital do estado da Paraíba, localizada na região Nordeste do Brasil, onde se tem uma população de 723.515 habitantes (Censo IBGE, 2010) e densidade populacional de 62,95 hab/ha, ocupando, desse modo, uma área de $11.493,14$ ha. Se fosse adotada a recomendação do PNUD/
8. Disponível em: <http://maps.grida.no/ go/graphic/urban-density-and-transportrelated-energy-consumption $>$. Acesso em: 11/08/2011.

Figura 5 • Relação entre transporte e consumo de energia (Gigajoules per capita por ano) em conforme à densidade urbana (habitantes por ha).

Fonte: Silva (2011) apud Newman \& Kenworthy, 1989; Atlas Environnement du Le Monde Diplomatique, $2007^{8}$.

Figura 6 • Gráfico do estudo de Newman e Kenworthy em 1989, que se refere à demonstração de uma relação entre a densidade urbana global ( $\mathrm{m}^{2} /$ pessoa) e uso de energia de transporte (gigajoule/ pessoa).

Fonte: Silva (2011) apud Newman \& Kenworthy, 1989.

Cadernos de Arquitetura e Urbanismo, v.23, n.33, 2ºm. 2016 
SUDENE, para o Nordeste brasileiro, de 250 hab/ha, a área ocupada se reduziria para 2.699,05 ha. Ainda, se fosse adotada a densidade considerada ótima, do ponto de vista do aproveitamento da infraestrutura e dos provimentos urbanos (400 hab/ha), a área ocupada chegaria a apenas 1.686,91 ha, ou seja, a área necessária seria apenas $14,69 \%$ da área atualmente ocupada.

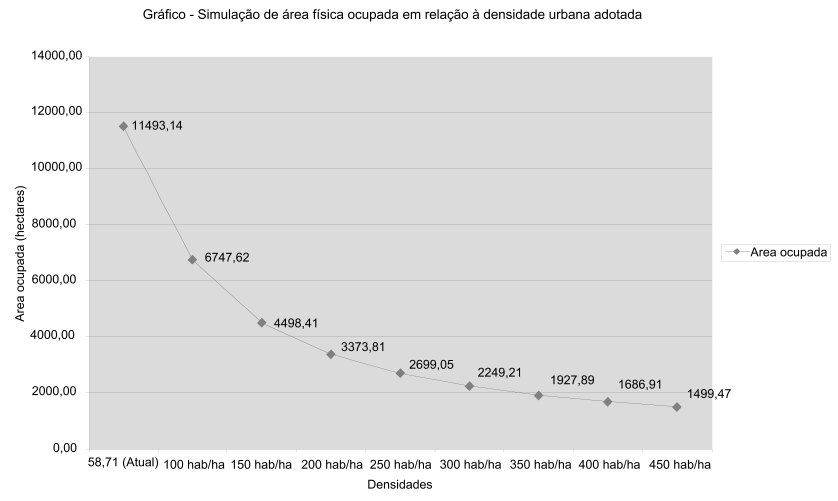

A densidade, contudo, por si só, não informa totalmente a eficiência interna de aproveitamento dos espaços e de articulação e integração entre os diversos usos. Uma densidade verticalizada, mas com grandes distâncias entre os seus elementos internos também geraria uma estrutura que, embora relativamente densa, apresenta também grande descontinuidade interna. A condição mais favorável é a que, além da densidade e das adequações morfológicas, também apresentasse uma articulação interna mais favorável às interfaces funcionais intraurbanas. Assim, a economia espacial e ambiental também estaria acompanhada por uma aproximação forte entre os usos, a melhoria das acessibilidades e, portanto, também das oportunidades para cada cidadão individualmente.

Além da economia da área natural ou rural ocupada precocemente pela urbanização periférica, o adensamento, com menor quantidade de vazios e áreas de preservação internas à estrutura urbana, viabilizaria melhor a sua conservação por meio de usos compatíveis e socialmente úteis, como parques e florestas urbanas tratadas. Até mesmo as áreas verdes internas merecem melhor gestão e dimensionamentos na escala humana e ambiental, não a escala do automóvel, como adotada em muitos casos.

As grandes quantidades de áreas verdes a serem preservadas e posteriormente destinadas a uma função socioambiental, em uma cidade dispersa, dificultam a viabilidade de seu tratamento adequado e as expõe à pressão demográfica, à agressão, aos "conflitos de borda" e à ocupação inadequada ${ }^{9}$. Esses fenômenos são particularmente notados em regiões mais pobres, onde existem menores recursos financeiros para a implantação de equipamentos e infraestruturas. Por outro lado, paulatinamente, as áreas públicas tendem a se tornar áreas privadas, conforme as atuações e as forças do mercado especulativo imobiliário sobre a cidade.
9. Em um ambiente urbano, a preservação e a conservação da natureza, se fazem mais eficientemente, não por meio da intocabilidade ou da conservação pura e simples, mas em decorrência da atribuição de uma função social mais adequada à sua caracteristica como area aà ser preservada. Essta percepção da associação entre a necessidade da preservação e a utilização coletiva do espaço leva o cidadão a colocar-se em uma posição bem mais amistosa e solidária em relação ao espaço verde.

Figura 7 • Simulação da área física ocupada pela população da cidade de João Pessoa-PB, em relação a diferentes densidades urbanas supostamente adotadas.

Fonte: Adaptado de Ribeiro \& Oashi (2010). 
Na construção material da cidade e de seus dispositivos técnico-espaciais, o adensamento permitiria também uma economia considerável na infraestrutura, na rede de drenagem urbana e, principalmente, no que diz respeito ao sistema de circulação e transporte intraurbano. Essa economia material na construção e funcionamento da cidade já vem sendo considerada por muitos autores, tais como Rogers \& Gumuchdjian (2005), em "Cities for a small planet" ou Mascaró (2004). A redução espacial e o adensamento populacional, além de minimizar as distâncias (viabilizando deslocamentos não motorizados e reduzindo o consumo nos deslocamentos motorizados), reduziria também o consumo material para a construção da cidade e tornaria melhor o seu funcionamento. Seu funcionamento consumiria menos tempo, menos espaços, menos energia e, portanto, teria um nível de emissão de poluentes veiculares bem menor. A concentração e a densidade populacional viabilizariam mais facilmente sistemas de transportes de maior capacidade e eficiência e fontes energéticas não emissoras, como os VLT's elétricos e outros.

Nesse sentido, as cidades compactas, ao contrário do que propagam alguns autores que afirmam ser cidades sufocantes, com alta concentração de poluentes e ruidosas, podem ter uma característica exatamente inversa, pela redução do uso do automóvel, que é a principal fonte de poluentes atmosféricos e uma das principais fontes de ruído urbano. Se trabalhos como o de Maignant (2005), por exemplo, não chegam a resultados favoráveis às cidades compactas, afirmando que as mesmas apresentam maior concentração de poluentes, em virtude de sua maior compartimentação, tal fato decorre de uma hipótese equivocada, em que o nível de emissão, supostamente, seria igual para os dois casos. No entanto, em cidades compactas, a redução da emissão na fonte, permitida pela aproximação entre os usos e pelas novas possibilidades de deslocamento, em substituição ao automóvel, seria a sua maior contribuição. A compartimentação atribuída ao adensamento não acumularia poluentes se eles não forem emitidos em seu interior.

Por outro lado, os impactos podem ser minimizados ou potencializados conforme o grau de planejamento urbano e investimentos em modais mais eficientes e menos poluentes, e essa assertiva é válida tanto para a cidade compacta como para a cidade dispersa, mesmo sendo esta última, em média, a que maior polui e emite gases estufa/per capita. (Figura 8)

Além disso, as condições de dispersão não são tão diretamente ligadas à densidade de ocupação. Existem outros fatores, de caráter qualitativo, como a porosidade estrutural que, mesmo em condições de densas ocupações, poderia permitir melhores condições de dispersão local e minimizar sua concentração interna aos ambientes urbanos. Para uma mesma densidade, seriam possíveis vários graus de porosidade ou permeabilidade de suas estruturas edificadas e entre elas. Uma melhor porosidade permitiria uma boa renovação de ar, ainda em ambientes de alta densidade construída. Esse princípio também foi adotado no urbanismo modernista, no 
entanto naquele, as distâncias entre os volumes edificados foram dimensionadas, mas em função da previsão de grandes fluxos de automóveis. Esse princípio compacto baseia-se no equilíbrio da circulação com sistemas não motorizados ou sistemas motorizados de transporte coletivo (de alto rendimento e menor emissão per capita) e, portanto, suas dimensões poderiam ser menores e mais eficientes e higienizados.

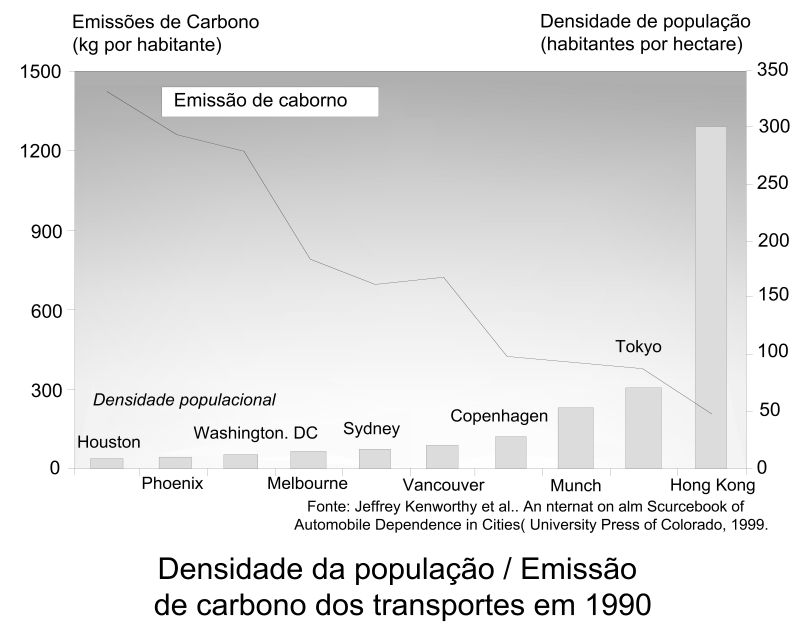

\section{A compacidade urbana e a qualidade de vida}

Além dos aspectos ambientais citados, uma argumentação frequente, entre alguns autores sobre a cidade compacta, é que ela ofereceria menor índice de qualidade de vida, pela sobrecarga dos equipamentos e serviços urbanos, menor quantidade de áreas verdes e espaços intraurbanos e, ainda, menor presença de natureza nos espaços internos da cidade. $\mathrm{Na}$ realidade, esse pensamento faz parte de uma série de mitos urbanos. Ao contrário do que geralmente se imagina, as cidades mais compactas podem ser menos poluídas, uma vez que minimizam o efeito gerador principal (forte utilização de fontes veiculares individuais).

As densidades mais elevadas, se adotadas com uma morfologia conveniente, longe de sobrecarregar os serviços públicos e os equipamentos urbanos, permitem otimizar qualitativamente o seu uso, pelo melhor aproveitamento social do espaço e pela melhor acessibilidade. Por exemplo, o provimento de escolas para setores urbanos de baixa densidade ou se dá por meio de um número muito maior de pequenas escolas, dispersas no território, funcionando frequentemente com recursos mínimos, ou ocorre com equipamentos maiores, localizados de forma mais esparsa e com dificuldades de acesso pelas distâncias.

Na modalidade compacta, poder-se-iam ter equipamentos mais completos (voltados a um maior número de usuários), com maiores recursos internos (bibliotecas bem formadas, laboratórios, equipamentos de informática e pesquisa, equipamentos esportivos e de prática profissional, etc) e com um
Figura 8 - Densidade e emissão de carbono.

Fonte: Adaptado de Kenworthy, J. et al. (1999). 
índice de proximidade que iria permitir, inclusive, maior número de opções para cada família usuária. Na prática, haveria menos equipamentos, mas equipamentos mais completos e mais próximos às habitações (melhoria qualitativa), havendo maior sobreposição de áreas de influência, melhorando o número de opções de escolha (melhoria qualitativa). É bem verdade que, em condições de densidades mais altas, torna-se mais difícil encontrar lotes de grande tamanho, capazes de comportar tais equipamentos; ou ainda, sua aquisição poderia ser mais onerosa. No entanto, tais custos seriam compensados pela redução do número de equipamentos necessários, bem como por decorrência de ferramentas legais e tributárias compensadoras dos gastos públicos, face à valorização das áreas consolidadas. ${ }^{10}$

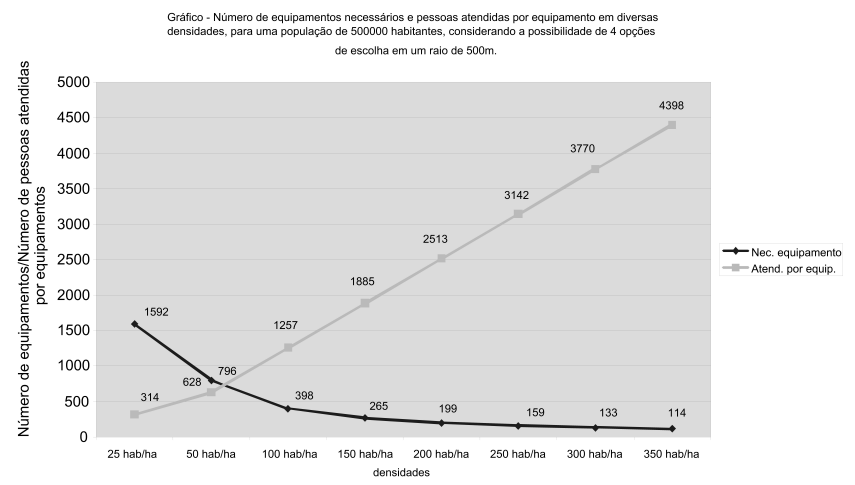

Evidentemente, em equipamentos que exijam limites de escala ou que o número de usuários seja idealmente mais limitado, como no caso de escolas infantis e de ensino fundamental, onde os equipamentos deveriam ter uma escala mais compatível com a pequena idade dos usuários, a adoção desse princípio (poucos, mas grandes equipamentos) poderia não ser a mais indicada. Tal fato seria problemático nos níveis mais altos de densidades, contudo, seria mais facilmente viabilizado em segmentos de densidades brutas médias em torno de 200 hab./ha. Em uma cidade densa, as famílias com filhos pequenos normalmente buscam áreas com densidades um pouco menores. Em algumas cidades mais densas, existem escolas infantis bem distribuídas, ocupando áreas anexas a usos residenciais, e acompanhadas por pequenos jardins de proximidade equipados para o lazer infantil. Essa conclusão também é afirmada por Haugley (2005), que ressalta ainda que, em densidades maiores, as famílias, em geral, são de dimensões mais reduzidas e, proporcionalmente, demandam menos equipamentos escolares, reduzindo, portanto, a sobrecarga dos equipamentos das áreas centrais.

Mas, seguramente, o aspecto mais criticado pelos opositores da cidade compacta seria o de sua suposta falta de espaços verdes e áreas livres e do pequeno contato com a natureza que o habitante de uma cidade compacta teria. Nas hipóteses formuladas pelos partidários desse raciocínio, está a ideia de que os habitantes de tal cidade, tendo menor contato com a natureza, no espaço intraurbano, iria fatalmente
10. Esta aquisição ou disponibilização de terrenos também seria facilitada com a redistribuição de áreas, facilitada pela compactação urbana. Os projetos de urbanização e novos loteamentos deveriam conceder mais áreas para equipamentos públicos e menos áreas para sistema viário, uma vez que, em condições de maior compacidade, a demanda quantitativa de vias seria bem menor e a utilização de sistemas mais eficientes, com menor consumo de espaço, seria bem maior.

Figura 9 • Número de equipamentos necessários, em uma simulação para uma cidade de 500 mil habitantes, para atendimento em diversas densidades urbanas, considerando a possibilidade de 4 opções de escolha, acessível em um raio de 500 metros; e População atendida por equipamento, considerando-se os mesmos critérios.

Fonte: Adaptado de Ribeiro e Cop (2010). 
buscar residências secundárias em áreas naturais, piorando o problema da dispersão.

Poderíamos, no entanto, testar essa crítica em alguns aspectos, notadamente os seguintes: i) distância média de cada habitante em relação à natureza interurbana; ii) possibilidades e potencialidades de uso e contato com áreas verdes interurbanas e, ainda, iii) possibilidades técnicas de arborização de vias urbanas.

\section{i) Distância média dos habitantes em relação à natureza interurbana}

Em uma cidade mais dispersa, ainda que se possa encontrar, em suas áreas intersticiais, uma grande quantidade de cobertura vegetal, elas são, na realidade, vazios urbanos; áreas sujeitas a modificações de uso repentinamente ou ao longo do tempo. A natureza ainda não ocupada por uso urbano se torna mais distante. Em uma simulação para uma cidade isotrópica teórica de 400.000 habitantes, a distância média dos seus cidadãos, em relação à área natural interurbana, aumenta consideravelmente se suas densidades forem menores. Por exemplo: para um aumento da densidade urbana populacional adotada, de 50 hab/ha para 100 hab/ha, a cidade reduziria o seu raio e a sua área, e a distância média dos cidadãos para a área natural externa cairia de $5,05 \mathrm{~km}$ para 3,57 km (Figura 10).

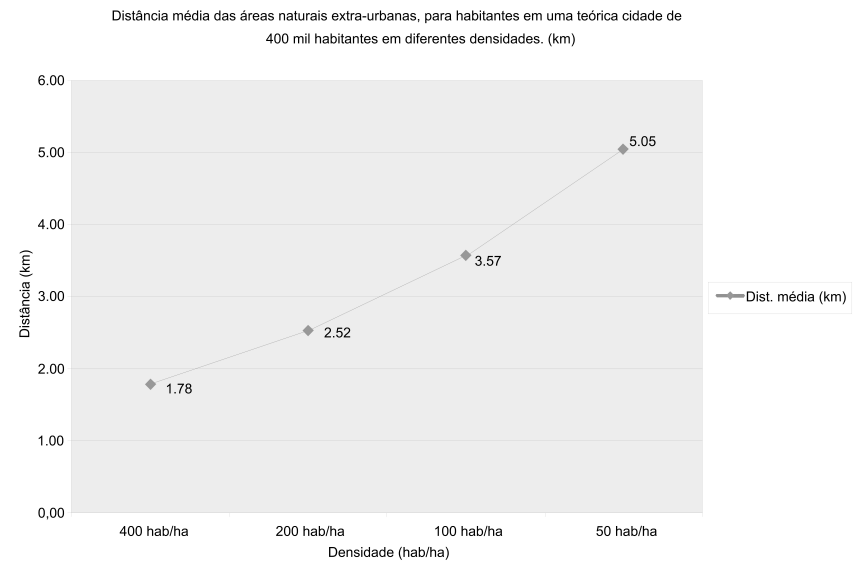

ii) Possibilidades de uso e contato com áreas verdes intraurbanas

Se fossem adotados vários pequenos parques (bem mais adequados à estrutura de uma cidade compacta) em substituição a alguns poucos grandes parques, poder-se-ia obter uma extensão de borda bem maior, concomitantemente com uma melhor distribuição espacial na cidade, o que proporcionaria melhoria significativa do contato do habitante urbano com a paisagem natural e com as possibilidades de desfrute das áreas verdes. Nessa contribuição, estariam também alguns efeitos microclimáticos, que são particularmente melhor percebidos nas bordas dos parques ${ }^{11}$. Veja-se a simulação sobre a extensão relativa de áreas de parques, em diferentes classes de dimensões e diferentes fracionamentos,
11. Os "efeitos de borda", na visão dos urbanistas ecólogos e tendo como referência as florestas naturais, seriam mais negativos que positivos, pois dizem respeito ao impacto do ambiente urbano sobre o bosque natural, com foco nesse último. No entanto, nas áreas verdes urbanas, onde o foco da atenção é o meio antrópico e não propriamente os ecossistemas, os efeitos seriam considerados sempre positivos, tais como os efeitos microclimáticos, paisagísticos, amenização, acessibilidades ao lazer, etc.

\author{
Figura 10 • Distância média (em km) \\ das áreas naturais periurbanas, para \\ habitantes de uma teórica cidade \\ isotrópica de 400 mil habitantes, em \\ diferentes condições de densidades \\ populacionais brutas. \\ Fonte: Adaptado de Ribeiro e Cop (2010).
}


na Figura 11 indicada adiante. Da mesma maneira, as áreas verdes intraurbanas de grande porte, embora sejam bastante positivas em sua contribuição paraclimática e como oferta de áreas de lazer, se fossem fracionadas em vários parques menores, teria sua utilização bastante otimizada. Isso aumentaria a superfície utilizável, principalmente na frequência diária. Vários autores já constataram que os grandes parques têm um percentual pequeno de sua área utilizada, particularmente em dias úteis, enquanto os pequenos parques têm maior percentual de utilização do espaço.

Extensão relativa de bordas de parques urbanos, por dimensão e por repartição da área total $(\mathrm{ml} / \mathrm{km} 2)$

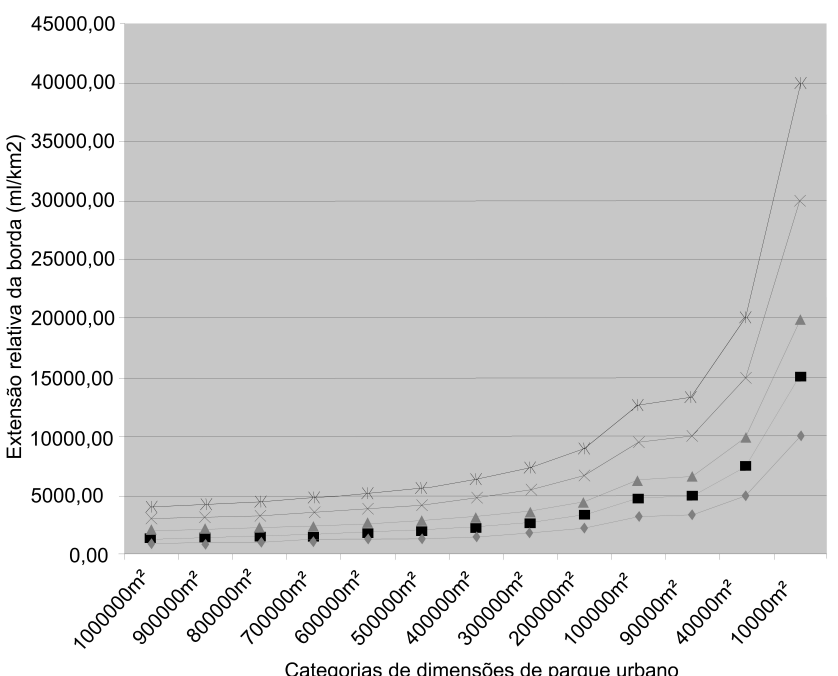

Categorias de dimensões de parque urbano
Portanto, além de um ganho na eficiência da utilização do espaço, ter-se-ia, nesses casos, um ganho no caráter público do espaço, no sentido de que seriam espaços onde, pela sua escala, os cidadãos não apenas se encontram com a natureza, mas também se encontram entre si e realizam sua convivência social. Gorra-Gobin (1998 e 2001) ressalta a importância dos aspectos ambientais e sociais das áreas verdes, mostrando os seus elementos vegetais (de importância ambiental) e seus elementos minerais, que, juntamente com os gramados, servem como piso ou base física para os relacionamentos sociais.

No gráfico indicado na Figura 12, a seguir, pode-se observar que, em caso de parques fechados com uma única abertura de um dos lados, apenas os parques pequenos (na faixa de $10.000 \mathrm{~m} 2$ ) é que têm seu espaço plenamente utilizado, em seu funcionamento diário. No caso de parques com área de 1.000.000 m2, o percentual de área utilizada (em dias úteis) cai para aproximadamente $2 \%$ apenas. Portanto, para a concepção de uma cidade compacta, também seria necessário a readaptação novamente para a escala humana. A cidade compacta, portanto, pode representar uma re-humanização do espaço urbano.
- Extensão de bordas por dimensão de área de parque urbano, em espaço único e em divisões

- 2 parques

$\triangle 4$ parques

8 parques

16 parques

Figura 11 • Simulação de diferentes extensões relativas $(\mathrm{ml} / \mathrm{km} 2)$ de bordas de parques urbanos por classe de dimensão e por fracionamento da área total destinada à parques urbanos.

Fonte: Adaptado de Ribeiro e Cop (2010). 


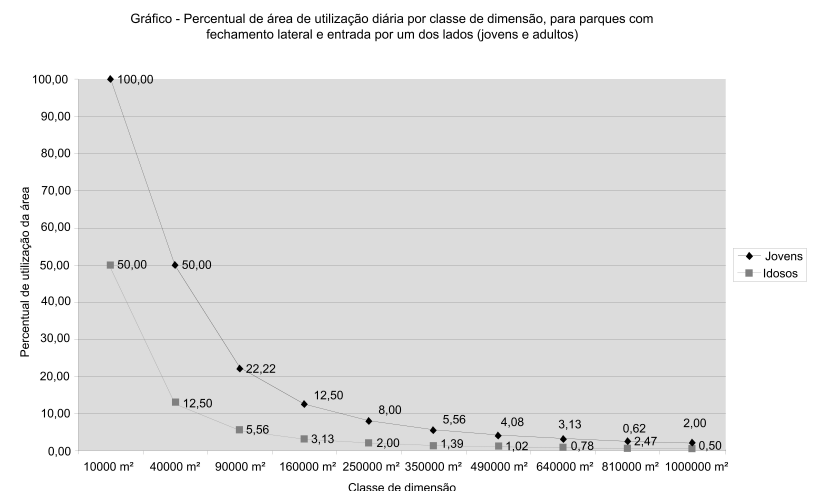

iii) Possibilidades técnicas de arborização de vias urbanas

Se sob o aspecto das áreas verdes tem-se uma melhor otimização da sua utilização social no caso da compactação, no lado da arborização do sistema viário, tem-se a observação de que a necessidade de superdimensionamento e multiplicação das faixas viárias de circulação veicular ocorrem mais comumente em condições de dispersão urbana ou fusão da estrutura urbana com a estrutura regional.

Em uma situação de compacidade urbana, viabilizar-se-ia muito mais os sistemas mais eficientes de circulação, permitindo a liberação de faixas para arborização urbana contínua. Como assinala Junke (1968), a capacidade de circulação em cada faixa de 3 metros de largura de via, em períodos de pico de circulação em áreas centrais urbanas, é bem desfavorável ao automóvel, ao mesmo tempo em que é bastante favorável aos sistemas individuais não motorizados (pedestrianismo e ciclismo) e aos sistemas coletivos de transportes, conforme se pode observar no Quadro 2 indicado adiante. Portanto, a economia de faixas viárias decorrentes da compactação e da viabilização otimizada do emprego de transportes motorizados coletivos e de circulação não motorizadas individuais permitiria a utilização das áreas que seriam alocadas à circulação veicular, para arborização, ampliando, dessa forma, o contato do cidadão com o ambiente ameno, verde e sombreado das árvores. Nesse caso, no entanto, haveria necessidade de se ajustar o perfil das calhas viárias urbanas (compartimento resultante entre os edifícios circundantes e a calha viária), de forma que sua relação de aspecto (altura/largura) não tenha índices que venham a prejudicar ou dificultar o crescimento da vegetação arbórea (ou pelo sombreamento ou pela estreiteza da calha).

\begin{tabular}{|l|r|l|l|l|}
\hline $\begin{array}{l}\text { Modos de } \\
\text { transporte }\end{array}$ & $\begin{array}{l}\text { Capacidade } \\
\text { máxima por hora } \\
\text { (pass/hora) }\end{array}$ & $\begin{array}{l}\text { Velocidade } \\
\text { comercial } \\
\text { média } \\
\text { (km/hora) }\end{array}$ & $\begin{array}{l}\text { Poténcia máxima } \\
\text { de circulação } \\
\text { (pass.km/hora) }\end{array}$ & $\begin{array}{l}\text { Relação das } \\
\text { capacidades em } \\
\text { relação ao automóvel }\end{array}$ \\
\hline Pedestre & 16.000 & 4 & 64.000 & 4,5 \\
\hline Bicicletas & 5.400 & 12 & 65.000 & 4,5 \\
\hline Automóvel & 1.200 & 12 & 14.400 & 1 \\
\hline Onibus (55lug) & 5.600 & 10 & 56.000 & 6,5 \\
\hline Onibus (83 lug) & 8.300 & 10 & 83.000 & 42,0 \\
\hline VLT (simples) & 24.000 & 10 & 240.000 & 6 \\
\hline VLT (duplo/autom) & 40.000 & 15 & 600.000 & \\
\hline
\end{tabular}

Figura 12 • Percentual médio de utilização diária do espaço interno de parques urbanos fechados, com uma única abertura, para diferentes condições de dimensionamento.

Fonte: Adaptado de Ribeiro e Cop (2010).
Quadro 2 • Capacidade e Potência de circulação de uma faixa viária de 3 metros de largura para diferentes modos de deslocamentos, em áreas urbanas e hora de pico.

Fonte: Adaptado de Junke (1968). 
Dessa forma, a demanda adicional de circulação, com a compactação urbana, poderia ser bem atendida com a substituição das faixas para automóveis para vias pedestrianizadas, 4,5 vezes mais eficientes em pequenas distâncias, ou por corredores de ônibus ou, preferencialmente, o VLT (Veículo Leve sobre Trilhos ou Light Rail), sendo este 16,5 vezes mais eficiente. As faixas excedentes poderiam ser transformadas em faixas verdes. No caso do VLT, a própria faixa utilizada pode ser gramada, permitindo um espaço viário que se aproxima de um verdadeiro parque linear, concluindo-se pela ideia das vantagens espaciais que podem ser alcançadas com o padrão de cidades menos estendidas.

\section{A compacidade urbana e a justiça social}

Além dos efeitos ecológico-econômicos, bem com os efeitos sobre a qualidade de vida urbana aqui apresentados, se poder-se-iaia também sugerir possíveis benefícios enquanto justiça social, uma vez que a cidade compacta tornaria as acessibilidades e as oportunidades urbanas mais similares e reduziria (ao menos espacialmente) a segregação social, contribuindo para uma melhor equidade. Esste aspecto completaria os elementos básicos componentes da sustentabilidade. (ambientalmente adequado, economicamente viável e socialmente justo).

A melhor distribuição das áreas verdes na estrutura urbana também organiza espacialmente melhor o seu impacto positivo sobre o valor da terra urbana. Nesse sentidoDesse modo, até mesmo a especulação sobre o valor imobiliário, que normalmente acontece em áreas urbanas vizinhas aos parques e áreas verdes, seria mais diluída, pela melhor distribuição espacial do "bem". AssimNesse sentido, uma cidade compacta seria caracterizada por uma cidade de investimentos e de oportunidades mais diluídas, mas uma cidade de menor especulação e melhor justiça social. A preferência dos especuladores por privilégios e grandes lucros, em detrimento da coletividade, seria minimizada em uma condição de compacidade urbana, pela nova escala e organização espacial e funcional produzida.

De fato, talvez inspirados pela abordagem de Harvey (1980) sobre as relações existentes entre a justiça social e o contexto urbano, autores como Burton (2001), por meio de análise própria e de outros autores sobre o assunto, vêm tentando definir influências da compacidade urbana sobre a justiça social. Na abordagem, vários aspectos também se sobrepõem àqueles considerados na avaliação da qualidade de vida urbana. A partir de um quadro montado por Burton (2001), em queonde se estabeleceu uma série de fatores positivos e negativos e as influências que a compacidade urbana teria sobre elesos mesmos, apresenta-se aqui novo quadro complementado (Quadro 3), baseado em uma nova análise própria, e considerando a colocação de outros autores 


\begin{tabular}{|c|c|c|c|c|}
\hline $\begin{array}{c}\text { Fatores } \\
\text { considerados }\end{array}$ & $\begin{array}{l}\text { Avaliação da } \\
\text { influência }\end{array}$ & $\begin{array}{l}\text { Consensual/ } \\
\text { Polêmica }\end{array}$ & $\begin{array}{c}\text { Autores } \\
\text { considerados }\end{array}$ & Contribuição própria à análise \\
\hline $\begin{array}{l}\text { Melhores } \\
\text { acessos às } \\
\text { oportunidades }\end{array}$ & Positiva & Consensual & $\begin{array}{l}\text { Burton (2001); } \\
\text { Rees (1988); } \\
\text { Bromley \& } \\
\text { Thomas (1993) }\end{array}$ & $\begin{array}{l}\text { Inquestionável, é uma das } \\
\text { contribuições mais claras. }\end{array}$ \\
\hline $\begin{array}{l}\text { Melhores } \\
\text { indices de } \\
\text { acesso a } \\
\text { empregos }\end{array}$ & Incerta & $\begin{array}{l}\text { Não } \\
\text { consensual }\end{array}$ & $\begin{array}{l}\text { Beer (1994); } \\
\text { Laws (1994); } \\
\text { Ribeiro (2008) }\end{array}$ & $\begin{array}{c}\text { A melhoria da acessibilidade fisica ao } \\
\text { emprego é inquestionável. Mas } \\
\text { existem outros fatores ainda mais } \\
\text { dominantes, como a política e a } \\
\text { globalização. }\end{array}$ \\
\hline $\begin{array}{l}\text { Pior acesso a } \\
\text { áreas verdes }\end{array}$ & $\begin{array}{c}\text { Injustamente } \\
\text { considerada } \\
\text { negativa pela } \\
\text { maioria dos } \\
\text { autores }\end{array}$ & $\begin{array}{l}\text { Não } \\
\text { consensual }\end{array}$ & $\begin{array}{l}\text { Breheny (1992); } \\
\text { Knight (1996); } \\
\text { Ribeiro (2008) }\end{array}$ & $\begin{array}{l}\text { A compacidade urbana não significa } \\
\text { necessariamente escassez de espaços } \\
\text { verdes. Se bem dimensionados, sua } \\
\text { utilização seria apenas mais eficiente. }\end{array}$ \\
\hline $\begin{array}{l}\text { Grandes } \\
\text { oportunidades } \\
\text { para bicicletas e } \\
\text { caminhar a pé }\end{array}$ & $\begin{array}{l}\text { Considerada } \\
\text { Positiva, mas } \\
\text { ambigua }\end{array}$ & $\begin{array}{c}\text { Não } \\
\text { totalmente } \\
\text { consensual }\end{array}$ & $\begin{array}{l}\text { Boume (1992); } \\
\text { Newmann (1992) }\end{array}$ & $\begin{array}{l}\text { A compacidade melhora estas } \\
\text { possibilidades, por tomar as } \\
\text { distâncias mais viáveis, embora } \\
\text { alguns autores considerem o } \\
\text { adensamento como forte inibidor } \\
\text { do uso da bicicleta. }\end{array}$ \\
\hline $\begin{array}{l}\text { Melhoria do } \\
\text { transporte } \\
\text { coletivo }\end{array}$ & Positiva & $\begin{array}{l}\text { Totalmente } \\
\text { Consensual }\end{array}$ & $\begin{array}{l}\text { ECOTEC (1993); } \\
\text { Goodschild } \\
(1994)\end{array}$ & $\begin{array}{l}\text { Nenhum autor expressa dúvida desta } \\
\text { contribuição positiva. }\end{array}$ \\
\hline $\begin{array}{l}\text { Redução dos } \\
\text { espaços de vida } \\
\text { e convivência } \\
\text { doméstica }\end{array}$ & Negativa & $\begin{array}{l}\text { Não } \\
\text { consensual }\end{array}$ & $\begin{array}{l}\text { Forster (1994); } \\
\text { Stretton (1996) }\end{array}$ & $\begin{array}{l}\text { Os quintais e espaços domésticos } \\
\text { podem se reduzir, mas a menor perda } \\
\text { de tempo na circulação no meio } \\
\text { urbano pode aumentar convivência } \\
\text { familiar. }\end{array}$ \\
\hline $\begin{array}{l}\text { Influências } \\
\text { sobre a saúde } \\
\text { geral, fisica e } \\
\text { mental }\end{array}$ & $\begin{array}{c}\text { Considerada } \\
\text { Negativa, mas } \\
\text { ambígua }\end{array}$ & $\begin{array}{c}\text { Não } \\
\text { consensual }\end{array}$ & $\begin{array}{l}\text { Freemann (1992); } \\
\text { McLaren (1992) }\end{array}$ & $\begin{array}{l}\text { Embora doenças respiratórias sejam } \\
\text { mais comuns, há outras } \\
\text { compensações: se caminha mais e se } \\
\text { reduz o sedentarismo. }\end{array}$ \\
\hline $\begin{array}{l}\text { Redução do } \\
\text { Crime }\end{array}$ & Positiva & $\begin{array}{l}\text { Não } \\
\text { totalmente } \\
\text { consensual }\end{array}$ & $\begin{array}{c}\text { Elkin et al. } \\
\text { (1991); Petherick } \\
\text { (1991) }\end{array}$ & $\begin{array}{l}\text { A proximidade social e a } \\
\text { revalorização dos espaços públicos } \\
\text { como locais de encontro são aspectos } \\
\text { positivos. }\end{array}$ \\
\hline
\end{tabular}

Ainda que seja um tanto prematuro concluir que as estruturas urbanas compactas contribuam efetivamente para a justiça social, se poder-se-ia sugerir que: a melhoria da acessibilidade geral, de forma mais isonômica, não privilegiando os detentores e usuários do automóvel; a aproximação física não apenas entre os diferentes usos, mas também entre mais ricos e os mais pobres, com a redução da segregação socioespacial e, ainda, a melhoria da eficiência dos espaços públicos, como lócus do encontro social e da convivência, permitiriam vários ganhos de oportunidade no cenário social da vida urbana, com benefícios sensíveis para a aproximação, coesão e coparticipação no meio urbano.

Finalmente, a sustentabilidade urbana perpassa todos esses critérios discutidos por meio de teorias urbanas contemporâneas, que, se consideradas as condicionantes sociais, econômicas e ambientais, determinam a compacidade urbana a melhor relação de custo benefício e convívio urbano. Conceitualmente, as cidades sustentáveis devem atender à critérios definidos por sistemas urbanos de metabolismo circular, no qual a informação, energia e materiais (entradas do sistema urbano $\mathrm{x}$ dependência do sistema-entorno) são reciclados e/ ou reaproveitados por retroalimentação sistêmico, produzindo maior índice de neguentropia (entropia negativa), com menos resíduos e poluição (saídas dos sistema urbano minimizados). (Figura 13)
Quadro 3 - Fatores positivos e negativos da Cidade compacta para a justiça social. Fonte: Adaptado de Burton (2001). 


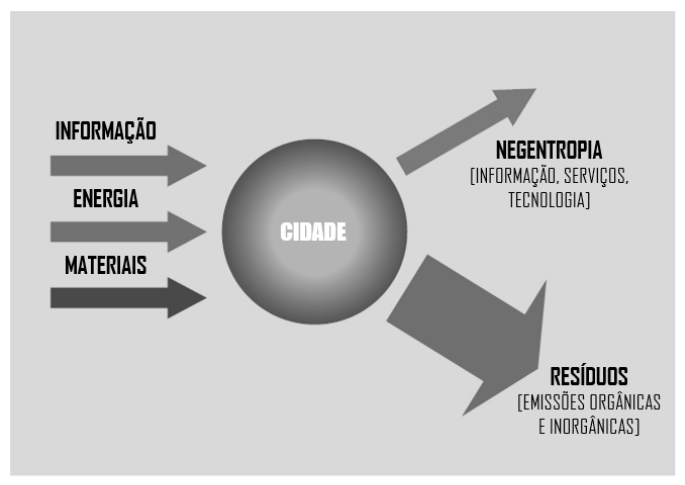

Cidades Atuais

\section{Considerações finais}

Este texto, ainda que não consiga dar a resposta definitiva sobre a vantagem de um sistema urbano compacto sobre o disperso, do ponto de vista ambiental, social e econômico, permite contribuir para uma melhor visibilidade e realismo na percepção da qualidade ambiental e de vida urbana a partir de critérios científicos comprovados por diversas pesquisas mundiais. Oferece ainda a contribuição para a desmistificação da associação de senso comum que se faz entre qualidade ambiental e presença de vazios urbanos, bastante habitual em uma estrutura dispersa, pois apontam os diversos impactos e custos provenientes de um modelo urbano de alto consumo energético, de recursos, de infraestrutura e manutenção.

Como discutido, na cidade dispersa existem muitos vazios urbanos, na maioria das vezes não tratados, ou terrenos privados subutilizados (sob especulação), e, o incentivo à dispersão diminui a pressão de ocupação sobre as áreas vazias já urbanizadas (essencialmente, de capital privado), ao passo que se incentiva a dispersão de novas áreas a serem valorizadas pelos investimentos de capital público. Assim, além de mais cara, a cidade dispersa estabelece um sistema de transferências de custos de urbanização para o estado, enquanto que o setor imobiliário adquire vultosos lucros na valorização do solo tanto em áreas centrais, quanto em áreas periurbanas, estsas mais baratas, mas que se valorizam consideravelmente com a ocupação e investimentos públicos. Muitos estudos demonstram que, face à existência de imóveis vazios ou subutilizados nas áreas centrais das cidades brasileiras, não seria necessária a expansão da ocupação em novas áreas, pois, o número de imóveis ou terrenos vazios são capazes de receber a demanda habitacional e de crescimento demográfico com qualidade ocupacional, desde que bem planejada e a partir de um desenho mais coeso enquanto morfologia.

Por sua vez, na cidade compacta, ainda que presentes em menor quantidade, os espaços livres e as áreas verdes, por

\section{Cidades Sustentáveis}

Figura $13 \bullet$ Energia e consumo nas cidades: Metabolismo Urbano Linear (das cidades atuais) e Circular (das cidades sustentáveis).

Fonte: Silva (2011) apud UN-HABITAT (2008: 156). 
serem dimensionados mais adequadamente e de forma viável, podem ser mais bem tratados e permitir melhor o encontro, a coesão social e a habitabilidade, já que poderão de fato serem utilizados por um maior número de pessoas. O espaço público é também um elemento de definição para a urbanidade e a vida coletiva da comunidade, assim, sua valorização, dimensionamento e proporção adequada, associado a equipamentos urbanos funcionais e acessíveis, transformam a relação de vizinhança num setor ou bairro da cidade.

Os aspectos mais consensuais a favor da cidade compacta são os que dizem respeito à acessibilidade, pela melhor proximidade que tais estruturas permitem e pela maior densidade, o que viabiliza sistemas de transportes mais eficientes, reduzindo o uso de sistemas individuais, economizando sensivelmente espaços e equipamentos. Assim, o barateamento dos sistemas modais e do custo de deslocamento per capita, associados com o menor consumo de combustíveis fósseis (cada vez mais caros e raros) e menores índices de emissão de gases, tornam-se pontos fortes em favor de uma política nacional de compactação urbana.

Os equipamentos públicos necessários poderão ser mais completos, uma vez que poderão atender mais pessoas e com acessibilidade facilitada. Como exemplo, escolas poderiam estar num raio de atendimento ideal $1<500 \mathrm{~m}$ de distância) e poderiam, pelo número de usuários, serem muito mais completas, com laboratórios, bibliotecas, equipamentos esportivos, menores custos de manutenção, etc.

Como visto, ainda que, embora em alguns casos, os indicadores quanti-qualitativos de um modelo mais expansivo pareçam melhores, pela quantidade disponibilizada (área verde per capita, por exemplo), por outro lado, a sua efetiva utilização e sua eficiência de uso, vêm ocorrer meIhor em cidades mais compactas, seja pela melhor distribuição espacial e acessibilidade, seja pelo dimensionamento mais apropriado, o que torna o seu potencial de utilização mais otimizado, pela melhor acessibilidade e equidade na distribuição social, no conjunto da estrutura urbana.

Dessa maneira, se pode-se afirmar que a cidade compacta pode ser mais verde, no sentido ecológico, que a cidade difusa, ainda que com um índice quantitativo (superfície verde) menor. Exatamente porque representa uma estrutura mais coesa e um funcionamento sistêmico mais harmônico, de melhor sinergia e menor entropia, enquanto pode também oferecer uma estrutura de áreas verdes mais reduzidas, mais eficientes, adequadas e qualitativamente melhores, de uso efetivo e consolidação mais viável, se comparada à uma estrutura urbana difusa (de baixa densidade ocupacional).

A redução da necessidade de áreas para automóveis e sistemas viários, nos espaços públicos, permite também maior destinação das mesmas à arborização e às áreas verdes, permitindo melhor contato da população 
com a arborização e a reocupação dos espaços, antes viários, por espaços de recriação, encontro social e lazer.

Por fim, a ideia de sentido de lugar e de pertencimento das pessoas é muito mais forte e recorrente em cidades mais compactas, como se verifica nas cidades antigas medievais ou no oriente médio. Geralmente, os espaços mais utilizados pelas pessoas são os que possuem uma escala humana adequada, que promove o encontro de vizinhos como os bancos, os tabuleiros de xadrez ou dama, a rua que permite a contemplação da paisagem ou o encontro de pessoas. Enfim, a vida urbana está atrelada ao Genius Loci, ao "espírito do lugar", e aosdos espaços públicos. E essa qualidade só é possível quando se promove o encontro de pessoas em espaços mais compactos e ricos em diversidade ocupacional e cultural.

Mas planejar cidades sustentáveis tem a ver com uma mudança cultural coletiva e de planejamento urbano e regional a partir da técnica e do conhecimento, no qual novos hábitos urbanos e de civilidade devem ser traduzidos ou promovidos por espaços de qualidade e culturalmente mais complexos e densos. Assim, a informação e a educação se tornam ferramentas vitais nesse processo de difusão do conhecimento e da promoção de "cidades inteligentes", tanto em nível de complexidade, tecnologia e difusão cultural, quanto no acesso de seus habitantes às novas oportunidades decorrentes dos ganhos educacionais, de comunidade e manifestações da cultura urbana e da técnica.

Desste modo, os ganhos socioeconômicos e ambientais tendem a se acentuar ao longo do tempo, preservando-se, pela compacidade, as áreas naturais de entorno urbano, como também pela redução dos elementos de entrada dos sistemas urbanos (energia, recursos, materiais e produtos), e redução dos impactos ambientais (menos emissão de gases poluentes, menos resíduos, menos consumo de solo rural), por meio da promoção de tecnologias verdes e sistemas cíclicos de reaproveitamento material. Essas seriam as premissas essenciais de um urbanismo mais sustentável e de um metabolismo circular para as cidades brasileiras do futuro, mas que, todavia, não necessitam serem novas cidades (ou outras cidades), mas, sim, cidades reabilitadas para novos usos mistos nos espaços de cidade já consolidados e, em muitos casos, subutilizados.

\section{Referências}

BOCHET, B., GAY, J-B \& PINI, G.. La ville dense et durable: un modèle européen pour la ville? Revue "Vues sur la ville" - Observatoire universitaire de la ville et du développement durable. Lyon: Géoconfluences - DGESCO - ENS de Lyon, 2004. Disponível em: < http://geoconfluences.ens-lyon.fr/doc/transv/DevDur/DevdurScient3.htm>, Acesso em: 05 de mar.ço de 2013. 
BURTON, E.. The compact city and social justice in Annals of Housing Studies Association Spring Conference Housing, Environment and Sustainability York: University of York, 2001.

CLAVAL, P.. La logique des villes Paris: Ed. Litec., 1981.

CLAVAL, P.. Reflexions sur la centralité. In Cahiers de Géographie au Québec, vol. 44 - no. 123, Dec. Québec: Département de géographie de l'Université Laval, 2000. Disponível em: < http://id.erudit.org/iderudit/022922ar>. Acesso em: 22 de mar.ço de 2013.

GHORRA-GOBIN, C.. La ville américaine: espace et société. Paris: Nathan, 1998.

GHORRA-GOBIN, C.. Les éspaces publics, capital social. Lyon: Geocarrefour, vol. 76 no. 1, pp. 05-11, 2001. Disponível em: <http://www.persee.fr/doc/geoca_1627-4873_2001_ num_76_1_2499>, Acesso em: 15 de fev.ereiro de 2013.

HARVEY, D.. A Justiça Social e a Cidade. Tradução: Armando Corrêa da Silva, São Paulo: Hucitec, 1980.

HAUGHLEY, R.. Higher development density: myth and fact. Los Angeles: Urban Land Institute - University publications, 2005.

KENWORTHY, J. etal. An international sourcebook of automobile dependence in cities Denver: UniversityPress of Colorado, 1999.

LEVY, J.. Le tournant géographique. Penser l'espace pour lire le monde. In Paris: Annales de Géographie, Année 2001 Vol. 110, Numéro 617 p. 104, 1994. Disponível em: <www.persee.fr/doc/geo_0003-4010_2001_ num_110_617_1808>, Acesso em: 22 de fev.ereiro de 2013.

MAIGNANT,G..Compacitéetformeurbaine, uneanalyseenvironnementale dans la perspective d'un développement urbain durable. Meudon: Publication de Recherche UMR 6012, CNRS, 2004.

MASCARÓ, J. L. \& YOSHINAGA, M.. Infra-estrutura urbana. Porto Alegre: Masquatro Editora, 2005.

MASCARÓ, J. L.. O custo das decisões arquitetônicas. 3a. edição. Porto Alegre: Masquatro Editora, 2004.

NEWMAN, P. \& KENWORTHY, J.. (1996) Formes de la ville et transports: vers un nouvel urbanisme. In: Cahiers de la I.A.U.R.I.F. no. $114-115,1996$.

NEWMAN, P. \& KENWORTHY, J.. (1999). Sustainability and cities: over-coming automobile dependence. London: Island Press, 1999.

NEWMAN, P. W. G. \& KENWORTHY, J. R.. Cities and Automobile Dependence. In An International Sourcebook. Aldershot, UK: Gower, 1989.

Peter Newman and Jeffrey Kenworthy. Urban Design to Re- 
duce Automobile Dependence. In Opolis: An International Journal of Suburban and Metropolitan Studies: Vol. 2: No. 1, Article 3. Disponível em: <http://repositories.cdlib.org/cssd/ opolis/vol2/iss1/art3>. Acesso em: 10 de agosto de 2016.

NEWTON, P.. Urban form and environmental performance, in Jenks, $M$. et al. Achieving a sustainable urban form. New York: Spon, 2000.

RIBEIRO, E. L \& OASHI, T. G.. Princípios de compactação urbana e qualidade de provimentos e de vida urbana. João Pessoa: PRPG/UFPB - Relatório PIBIC, 2010.

RIBEIRO, E. L \& COP, S. G.. Princípios de compactação urbana e qualidade ambiental urbana. João Pessoa: PRPG/UFPB - Relatório PIBIC, 2010.

RIBEIRO, E. L.. Cidades (in) sustentáveis - Reflexões e busca de modelos urbanos de menor entropia. João Pessoa: Editora Universitária / Casa do Livro, 2006.

RIBEIRO, E. L.. Transformations urbaines récentes en villes de taille moyenne en France et au Brésil dans le contexte de la globalisatio. Lyon-France: EVS-EDU - INSA - Lyon, 2009.

RIBEIRO, E. L; MOUSSET, J. A. \& MOUSSET, P.. L'inefficacité de l'espace public hétéronome dans la ville moderne et contemporaine. Annales du Seminaire "La ville Conviviale - INSA - Lyon - France, 2011.

ROGERS, R. \& GUMUCHDJIAN, Philip . Cities for a small planet. London: Paperback, 1997.

SILVA, G. J. A. da. Cidades sustentáveis: uma nova condição urbana. Estudo de Caso: Cuiabá-MT. Tese de Doutorado (Arquitetura e Urbanismo). Brasília: PPG-FAU-UnB, 2011.

SIMMONDS D. \& Coombe, D.. The transport implications of alternative urban forms, in Jenks, M. et al. Achieving a sustainable urban form. New York: Spon, 2000.

VIRILIO, P.. Cité, miroir, agonie. Paris: Les Analles de la recherche urbaine, no. 34, 1987.

Recebido em 28/03/2016

Aprovado em 10/08/2016 